\author{
M. Arminda PEDROSA ${ }^{1}$ and M. Helena DIAS ${ }^{2}$ \\ ${ }^{1}$ Departamento de Química, Faculdade de Ciências e Tecnologia, Universidade de Coimbra \\ ${ }^{2}$ Escola Superior de Educação, Instituto Politécnico de Coimbra
}

\title{
CHEMISTRY TEXTBOOK APPROACHES TO CHEMICAL EQUILIBRIUM AND STUDENT ALTERNATIVE CONCEPTIONS
}

Received: 21 September 1999; revised: 6 December 1999; accepted: 22 December 1999

\begin{abstract}
In the field of chemistry there has been considerable interest in discovering the reasons why many students have great difficulty in successfully developing a scientifically accepted understanding of chemical equilibrium. Research projects influenced and inspired by constructivism have been invaluable for identifying alternative conceptions that may turn into obstacles to meaningful learning of fundamental ideas regarding chemical equilibrium. Research findings provide evidence that misunderstandings of and related to chemical equilibrium are widespread at various levels of education, including prospective chemistry teachers. Language used in textbooks may give rise, or reinforce student alternative conceptions and research findings point to a direct relationship between language used in textbooks and some of the alternative conceptions students develop at various levels of school chemistry. Some of the students' alternative conceptions already identified, and available in literature, were the basis of an instrument devised to analyse chemistry textbooks used in secondary and tertiary education. This paper presents and discusses typical problematic language found in student textbooks in the light of students' current frameworks of understanding as described in literature. [Chem. Educ. Res. Pract. Eur.: 2000, 1, 227-236]
\end{abstract}

KEY WORDS: chemical equilibrium; reversible chemical reactions; learning problems; alternative conceptions; chemistry textbooks; language and meaning

\section{INTRODUCTION}

The diversity of views that students bring to chemistry instruction, especially alternative conceptions (ACs) that influence negatively their subsequent learning, have been documented in the science educational literature (Driver, Squires, Rushworth, \& WoodRobinson, 1994; Driver, Guesne, \& Tiberghien, 1985; McDermott, 1993; Osborne \& Freyberg, 1985; Griffiths, 1994; Garnett, Garnett, \& Hackling, 1995). Finding ways of preventing rote learning while encouraging and promoting meaningful learning (Novak, 1984 ) is a major concern underlying theoretical and classroom research. School chemistry, as school science, can be viewed as a means to enculturate or assimilate students into the subculture of science (Aikenhead, 1996) and the case for a re-evaluation of the methods and content of science education has been made by White (1992) and by Atkin and Helms (1993).

Constructivism regards teachers and students as learners (Gunstone, White, \& Fensham, 1988) and encourages the development of metacognitive strategies (Gunstone, 1994), a more reflective questioning, and science teaching strategies based on a diversity of activities involving social interactions and students' co-operation converging to the development and improvement of students' learning. 
Given the social nature of education, the variety of social communities and agents influencing teaching and learning, the complexity of roles played by them, and the underlying network - variety and complexity - of factors affecting learning and learners, various actions may be envisaged. However, chemistry education researchers share substantial responsibility to shorten the gap between research findings and actual curricular resources and teaching practices. Finding ways to get the message across other chemistry education communities and agents is crucial. To make student ACs available in literature accessible and purposeful for chemistry teachers, divulging and discussing them is an essential step towards that end.

To explore and use research findings to improve chemistry learning, improving curricular resources and teaching approaches appears both required and urgent to improve chemistry learning. Taking into account the apparent pre-eminence of textbooks in shaping curricula, and the contribution of instruction for dissemination of misconceptions on important chemistry topics (Haidar, 1997), it is sensible and adequate to initiate a coherent program beginning with textbooks followed by programs with chemistry teachers. In this study undertaken within the Portuguese educational context, the purpose was shaped by these major concerns and interests, focused on chemical equilibrium and related concepts.

Student ACs already identified are important in this regard, both as criteria and tools to help identify what Tsaparlis, Kousathana, \& Niaz (1998) called student 'core beliefs'. Then, the purpose of this research was to find out, taking into account selected ACs reported in literature, language and approaches that may contribute to give rise or reinforce ACs, or stimulate undesirable chemistry learning strategies, and to discuss implications for chemistry instruction. In short, the purpose of this study may be stated as follows:

1. To identify in textbooks widely used in Portuguese schools possible sources of ACs (reported in literature) concerning chemical equilibrium and related concepts.

2. To identify words or phrases commonly used in textbooks (and by chemists) that are likely to be misunderstood by students and eventually contribute to ACs referred to in 1 .

3. To offer some reflections and suggestions, based on 2., to contribute to raise upper secondary and university teachers' awareness of:

a) learning problems and difficulties concerning matter transformations involving reversible chemical reactions;

b) innovative and reflective strategies to stimulate and promote meaningful chemistry learning.

This preliminary study aims at contributing to make some of the student ACs available in literature regarding chemical equilibrium both accessible and purposeful for chemistry teachers. The stage herein reported concerned the identification of textbook excerpts which may encapsulate problematic language or implicit teaching approaches requiring reflection and revision in the light of the ACs reported in the literature, used as evidence of chemistry learning problems. It will then be argued that some of the wellestablished and widely used language in chemistry textbooks is likely to become problematic in teaching and learning situations, as it appears open to various interpretations some of which apparently related to students' ACs selected. The discussion undertaken encompasses suggestions with regard to language to prevent some of the learning problems pointed out and stresses the need of further research to extend this exploratory study and to evaluate the suitability and validity of the suggestions put forward.

\section{METHODOLOGY}


A number of research papers focusing on students' misunderstandings in chemistry were selected and studied (e.g. Johnstone, MacDonald, \& Webb, 1977; Camacho \& Good, 1989; Banerjee, 1991; Griffiths, 1994). For the purpose of chemistry textbook analysis on chemical equilibrium the Griffiths' list (1994, p. 5) has been a source of student ACs. A shorter list has been selected from it in conjunction with excerpts on this topic already selected and agreed upon by both researchers as being problematic. Our own experience with learning problems related to this topic (mainly in teaching upper secondary school chemistry and general chemistry, as well as in teacher training programmes where chemical equilibrium was dealt with) influenced both the first list of excerpts viewed as problematic and subsequently the student ACs selected. Table 1 presents the full list used in the analysis whose content deserved full agreement of both authors regarding both ACs selected and examples of excerpts likely to be related to them. The analysis was carried out by reading thoroughly through the texts to identify typical language, largely adopted and used within chemistry education contexts, that may contribute, reinforce or even give rise to student alternative conceptions related to chemical equilibrium. Chapters on chemical equilibrium were inspected. The analysis was extended to chapters where chemical reactions are approached assuming appropriate conditions to attain chemical equilibria, e.g., 'acid-base equilibria' and 'solubility equilibria' (Chang, 1991). Three textbooks for the last secondary school year - 12th year chemistry (Corrêa \& Basto, 1998; Gil, 1996; Leitão \& Carmona, 1997) and one university chemistry textbook (Chang, 1991) were analysed. They are all widely used in Portugal, the former three in schools and the latter in universities, especially in general chemistry courses. This exploratory study focused on textbooks used both in upper secondary (17-18 year old students) and university education due to similarities between 12th year chemistry and general chemistry courses regarding chemical equilibrium.

\section{RESULTS AND DISCUSSION}

The misunderstandings targeted in the preliminary analysis of textbooks are summarized in Table 1. This Table contains the target ACs and transcriptions of examples of problematic excerpts identified. The content of these excerpts allowed the identification of problematic language apparently related and linked to the students' ACs used in this study. The problematic excerpts identified as connected with ACs (see Table 1) support Anderson's (1990) and Garnett et al's (1995) view of a direct relationship between the language used in textbooks and some of the ACs that students develop at various levels of school chemistry. Such excerpts may be used by them to reinforce or defend their "core beliefs" (Tsaparlis, Kousathana, \& Niaz, 1998).

Nevertheless, other excerpts were identified as problematic as they appear inaccurate, are ambiguous or open to interpretations that might stimulate ACs' development, particularly the ones presented in Table 2. In addition to problematic language related to the ACs presented in Table 1, the scrutiny of textbooks allowed the identification of other language problems and, consequently, a broader characterization and discussion of problematic aspects of common approaches to chemical equilibrium. A summary of findings in this regard is presented in Table 2. This Table contains problematic words or phrases, a plausible intended meaning - apparently intended meaning, and examples of problematic excerpts found in the textbooks' scrutiny. Language problems identified are discussed with reference to approaches envisaged as underlying them. The discussion will be further developed to highlight alternative ways to approach and develop teaching to stimulate metacognition offering (more) reflective approaches to promote reflective teaching practices. 
TABLE 1. Student alternative conceptions on chemical equilibrium and related concepts used in textbook analysis and excerpts of problematic language identified.

\begin{tabular}{|c|c|}
\hline $\begin{array}{c}\text { Alternative Conception } \\
\text { Identification following Griffiths, } \\
\text { 1994, p. } 5\end{array}$ & Items of problematic language \\
\hline $\begin{array}{l}\text { A simple arithmetic relationship } \\
\text { exists between concentrations of } \\
\text { reactants and products, respectively. }\end{array}$ & $\begin{array}{l}\text { «When the system total pressure increases }\left(\mathrm{P}_{\mathrm{t}}>\mathrm{P}_{\mathrm{t}}\right) \text {, the } \\
\text { reaction quotient }\left(\mathrm{Q}=\mathrm{K} \times \mathrm{P}_{\mathrm{t}}\right) \text { increases. As equilibrium is } \\
\text { attained again when } \mathrm{K}=\mathrm{Kp} \text {, the quotient has to decrease, } \\
\text { that is, } \mathrm{Q} \text { has to decrease.» } \\
\text { «... the solubility in sea water has to be smaller than in pure } \\
\text { water, that is, } \mathrm{s}^{\prime}<\mathrm{s} \text {, as in this way only } \mathrm{K}_{\mathrm{sp}} \text { will not change.» } \\
\text { «This implies that the value of the product of the ion } \\
\text { concentrations in solution cannot exceed the } \mathrm{K}_{\mathrm{p}} \text { value.» }\end{array}$ \\
\hline $\begin{array}{l}\text { A catalyst affects the rate of the } \\
\text { forward and reverse reaction } \\
\text { differently. }\end{array}$ & $\begin{array}{l}\text { "To choose a temperature range high enough so that the rate } \\
\text { of the catalyzed reaction is not excessively low...» }\end{array}$ \\
\hline $\begin{array}{l}\text { The effect of imposing a constraint, } \\
\text { such as changing temperature or } \\
\text { pressure, on a system in equilibrium } \\
\text { is to cause a change in the amounts } \\
\text { of substances on one side of the } \\
\text { equation for the reaction (thus } \\
\text { representing a compartmentalized } \\
\text { view of equilibrium - as somehow } \\
\text { involving two disconnected sides of a } \\
\text { reaction). }\end{array}$ & $\begin{array}{l}\text { «There is a general rule that helps us to predict the direction } \\
\text { in which an equilibrium reaction will move when a change in } \\
\text { concentration, pressure, volume or temperature occurs.» } \\
\text { "[...] the net reaction would shift to the right until } \mathrm{Q}_{\mathrm{c}}=\mathrm{K}_{\mathrm{c} .} \text { " } \\
\text { «The temperature increase shifts the equilibrium in the } \\
\text { direction of the endothermic reaction.» } \\
\text { "A system pressure increase shifts the equilibrium in the } \\
\text { direction of less number of moles.» }\end{array}$ \\
\hline $\begin{array}{l}\text { At equilibrium no reaction is taking } \\
\text { place. }\end{array}$ & $\begin{array}{l}\text { «At equilibrium the net effect is zero because there is no net } \\
\text { reaction.» }\end{array}$ \\
\hline $\begin{array}{l}\text { Rate of reaction means the same as } \\
\text { extent of reaction. }\end{array}$ & $\begin{array}{l}\ll \text { For temperatures below } 1100^{\circ} \mathrm{C} \text {, the higher the pressure is, } \\
\text { the higher will be the conversion percentage; the time } \\
\text { interval to attain the equilibrium will also be higher } \\
{\left[\mathrm{N}_{2}(\mathrm{~g})+3 \mathrm{H}_{2}(\mathrm{~g}) \rightleftarrows 2 \mathrm{NH}_{3}(\mathrm{~g})\right] . »}\end{array}$ \\
\hline
\end{tabular}

A major problem identified concerns loose and ambiguous usage of the word system that appears to intercept a network of related problems. Learning about chemical equilibrium demands various conceptualizations if it is meant to promote understanding of the complex dynamics of transformations of substances into other substances. Adequate conceptualizations of system, reaction, reaction mixture, and equilibrium are required and these are beyond requirements to resolve prototype algorithmic exercises. Chemical equilibrium concepts are crucial to understanding the dynamics of equilibrium systems, or of changing systems evolving to equilibrium. Not only are they suitable but also required if (and when) transformations that substances undergo are partial, that is, when transformations undergone by substances leading to appearance of other substances are not complete or, in specific chemical language, when the chemical reaction concerned does not proceed to completion. Once chemical equilibrium is reached, the resulting system reaches an apparent stable "state in which there are no observable changes as the time goes by" (Chang, 1991, p. 596). This is interpreted in terms of two chemical reactions - direct and reverse - that are occurring or are supposed to be occurring, in a closed and thermally insulated container, both with the same rate. Thus two chemical reactions are occurring in spite of the apparent 
TABLE 2. Problematic words or phrases found in textbook scrutiny on chemical equilibrium and related concepts, apparent intended meanings viewed as required for chemical equilibrium meaningful learning and examples of problematic excerpts.

\begin{tabular}{|c|c|c|}
\hline $\begin{array}{c}\text { Problematic } \\
\text { word or } \\
\text { phrase }\end{array}$ & $\begin{array}{l}\text { Apparent } \\
\text { intended } \\
\text { meaning }\end{array}$ & Items of problematic language \\
\hline The reaction & $\begin{array}{l}\text { Reactions; } \\
\text { Equilibrium } \\
\text { system }\end{array}$ & $\begin{array}{l}\text { «Let us consider the reaction represented by the equation } \\
\mathrm{CO}(\mathrm{g})+2 \mathrm{H}_{2}(\mathrm{~g}) \rightleftarrows \mathrm{CH}_{3} \mathrm{OH}(\mathrm{g}) . » \\
\text { «When the reaction attains the equilibrium.» } \\
\text { «Let us consider one chemical equilibrium reaction....» } \\
\text { «... regarding the reaction at equilibrium ...» } \\
\text { «... and the reaction remains at the equilibrium state...» }\end{array}$ \\
\hline $\begin{array}{l}\text { The } \\
\text { equilibrium }\end{array}$ & $\begin{array}{l}\text { Equilibrium } \\
\text { system / } \\
\text { Equilibrium } \\
\text { reaction mixture }\end{array}$ & $\begin{array}{l}\text { «Equation of the equilibrium» } \\
\text { «After remembering some of the chemical equilibrium } \\
\text { characteristics, we will consider another general property of that } \\
\text { equilibrium ...» } \\
\text { "Calculate the concentration of all particles in the equilibrium } \\
\text { and the constant corresponding to the equilibrium ...» } \\
\text { «When the equilibrium represented by }[. . .] \text { is established.» } \\
\text { «The equation that represents the solubility equilibrium ...» }\end{array}$ \\
\hline $\begin{array}{l}\text { The } \\
\text { equilibrium }\end{array}$ & $\begin{array}{l}\begin{array}{l}\text { An equilibrium } \\
\text { state }\end{array} \\
\end{array}$ & $\begin{array}{l}\text { "As the equilibrium occurs after the solution is saturated }[\ldots] \text {, } \\
\text { that is, } \mathrm{K}_{\mathrm{e}}\left[\mathrm{CuSO}_{4}\right] \text { is constant in the equilibrium.» }\end{array}$ \\
\hline $\begin{array}{l}\text { Equilibrium } \\
\text { re- } \\
\text { establishment }\end{array}$ & $\begin{array}{l}\text { After another } \\
\text { equilibrium state } \\
\text { is attained } \\
\end{array}$ & $\begin{array}{l}\text { "After equilibrium re-establishment, calculate the concentration } \\
\text { of all the species in the container.» }\end{array}$ \\
\hline Equilibria & \begin{tabular}{|l|l} 
Equilibria \\
Equations
\end{tabular} & $\begin{array}{l}\text { «[...] on the reactions represented by the next equilibria } \\
\mathrm{N}_{2}(\mathrm{~g})+3 \mathrm{H}_{2}(\mathrm{~g}) \rightleftarrows 2 \mathrm{NH}_{3}(\mathrm{~g}) ; \\
2 \mathrm{SO}_{2}(\mathrm{~g})+\mathrm{O}_{2}(\mathrm{~g}) \rightleftarrows 2 \mathrm{SO}_{3}(\mathrm{~g})[\ldots] »\end{array}$ \\
\hline $\begin{array}{ll}\text { Evolution } \\
\text { (Equilibrium } / \\
\text { system } \\
\text { reaction) }\end{array}$ & $\begin{array}{l}\text { Changes on the } \\
\text { reaction mixture } \\
\text { upon disruption } \\
\text { of an equilibrium } \\
\text { state until } \\
\text { another } \\
\text { equilibrium is } \\
\text { attained }\end{array}$ & $\begin{array}{l}\text { "The equilibrium evolves to the forward direction.» } \\
\text { "The system evolves to the forward direction.» } \\
\text { "The reaction evolves to the forward direction.» }\end{array}$ \\
\hline $\begin{array}{l}\text { Displacement } \\
\text { (equilibrium } \\
\text { (equilibria) / } \\
\text { system } \\
\text { reaction) }\end{array}$ & & $\begin{array}{l}\text { «The equilibrium shifts forward.» } \\
\text { «The system shifts forward.» } \\
\text { «The reaction shifts forward.» } \\
\text { «The equilibrium will evolve until } \mathrm{K}_{\mathrm{p}}=\mathrm{Q} \text {, that is, the system } \\
\text { shifts to the reverse direction.» } \\
\text { «[...] the equilibria referred are much shifted to the right.» }\end{array}$ \\
\hline Displacement & & «The displacement can be attained .... \\
\hline $\begin{array}{l}\text { Equilibrium } \\
\text { position }\end{array}$ & $\begin{array}{l}\text { An equilibrium } \\
\text { state }\end{array}$ & $\begin{array}{l}\text { "Will the initial amount of the reactants }[\ldots . .] \text { be important to } \\
\text { define the equilibrium position?» } \\
\text { "... this does not influence the equilibrium position.» } \\
\text { «When the system changes from equilibrium position } 1 \text { to } \\
\text { equilibrium position } 2 \text {...» } \\
\qquad \rightarrow \text { THE TABLE CONTINUES ON NEXT PAGE }\end{array}$ \\
\hline
\end{tabular}




\section{$\rightarrow$ TABLE 2 CONTINUED}

\begin{tabular}{|c|c|c|}
\hline $\begin{array}{l}\text { Reversible } \\
\text { reaction }\end{array}$ & $\begin{array}{l}\text { Forward and } \\
\text { reverse reactions; } \\
\text { incomplete } \\
\text { chemical } \\
\text { transformations } \\
\end{array}$ & $\begin{array}{l}\text { «[...] as the reaction is reversible, the equilibrium will shift } \\
\text { forward ...» }\end{array}$ \\
\hline $\begin{array}{l}\text { Incomplete } \\
\text { chemical } \\
\text { reaction }\end{array}$ & & $\begin{array}{l}\text { "A chemical equation with two arrows } \rightleftarrows \text { or double arrow } \\
\text { represents an incomplete chemical reaction." }\end{array}$ \\
\hline The reaction & Reactions & $\begin{array}{l}\text { «The catalyst increases the reaction rate.» } \\
\text { «After equilibrium is attained, the reaction proceeds } \\
\text { (microscopically) in forward and reverse directions with the } \\
\text { same rates.» } \\
\text { «The equilibrium state can be attained when the reaction } \\
\text { proceeds in any two directions.» }\end{array}$ \\
\hline Insoluble salts & $\begin{array}{l}\text { Relative values } \\
\text { of ion } \\
\text { concentrations in } \\
\text { salt saturated } \\
\text { aqueous } \\
\text { solutions }\end{array}$ & $\begin{array}{l}\text { «Then, adding } \mathrm{HCl} \text { the ion } \mathrm{Ag}^{+} \text {is the only one that precipitates. } \\
\mathrm{Cu}^{2+} \text { and } \mathrm{Ca}^{2+} \text { remain in the solution. Similarly: } \\
\mathrm{K}_{\mathrm{sp}}\left(\mathrm{Ag}_{2} \mathrm{~S}\right)=6,310^{-50} ; \mathrm{K}_{\mathrm{sp}}(\mathrm{CuS})=4,010^{-36} ; \mathrm{K}_{\mathrm{sp}}(\mathrm{CaS}) \text { (very } \\
\text { soluble) } \\
\text { Silver and copper sulphides are practically insoluble. As } \mathrm{Ag} \\
\text { was already eliminated, } \mathrm{CuS} \text { will precipitate. } \\
\text { The ion } \mathrm{Cu}^{2+} \text { will be the one remaining in solution. According } \\
\text { to solubility products, } \\
\mathrm{K}_{\mathrm{sp}}\left(\mathrm{Ag}_{2} \mathrm{CO}_{3}\right)=8,110^{-23} ; \mathrm{K}_{\mathrm{sp}}\left(\mathrm{CuCO}_{3}\right)=2,310^{-10} ; \mathrm{K}_{\mathrm{sp}}\left(\mathrm{CaCO}_{3}\right) \\
\quad=4,510^{-9} \text {, } \\
\text { ions would precipitate. As ions } \mathrm{Ag}^{+} \text {and } \mathrm{Cu}^{2+} \text { were already } \\
\text { eliminated, } \mathrm{Ca}^{2+} \text { is the only one that precipitates.» }\end{array}$ \\
\hline \multirow{2}{*}{$\begin{array}{l}\text { Ion formed / } \\
\text { existing in } \\
\text { solubility } \\
\text { equilibrium }\end{array}$} & $\begin{array}{l}\text { Hydrated ions - } \\
\text { products of salt } \\
\text { dissolution }\end{array}$ & $\begin{array}{l}\text { "Adding an acid, increases the solubility when the ion formed } \\
\text { in the solubility equilibrium is a weak base ...»" }\end{array}$ \\
\hline & & $\begin{array}{l}\text { «If the Ksp value is very small, compared with the equilibrium } \\
\text { constant for the reaction that consumes the ion existing in the } \\
\text { solubility equilibrium, ...» }\end{array}$ \\
\hline The reaction & $*$ & «Any reaction with Kc $>>1$ occurs forward preferably.» \\
\hline
\end{tabular}

*The excerpt appears very ambiguous and misleading. It deserves deeper discussion.

[Emphasis (underlining) added]

contradiction with the well established reversible chemical reaction. While this phrase may work well among practising chemists, it is likely to be misleading within upper secondary and higher chemistry education. Textbooks do not adequately explore discussions of this issue. They often describe the components of selected examples of equilibria states and quickly jump to chemical equations stressing the replacement of $\rightarrow$ by $\rightleftarrows$ while providing brief information about the new representation. The idea of reversibility associated with this new representation was identified in the textbooks analyzed, e.g., "... where the double arrow ( $\rightleftarrows$ ) indicates that the process is reversible" (Chang, 1991, p. 596). The double arrow is supposed to represent two reactions occurring in the equilibrium system, however, it is often simply accompanied by a short statement like the reversible reaction. From then on, the textbooks analysed talk systematically about the reaction, rather than reactions. This 
language inaccuracy contradicts the essential idea that two reactions are occurring, or are supposed to be occurring, is likely to distort the intended meaning for this representation and contribute to different arrays of ACs.

The dynamics of reversible chemical reactions encompasses two types of dynamics different in nature, and it is important to distinguish them, especially in textbooks and teaching: the internal dynamics of the system itself; and the dynamics associated with the dynamic nature of the chemical reactions underlying evolutionary transformations in each system. The latter is at the heart of scientifically acceptable interpretations of the macroscopically observable changes and focuses on the sub-microscopic level of the system constituent particles (molecules, atoms or ions). A miscellany of different names and phrases, commonly used to describe and discuss variations in reaction mixtures while evolving towards equilibrium, was also found in the textbooks analysed (see Table 2).

There is a number of typical and well established situations where changes operated on an equilibrium system disrupt the equilibrium state and, under suitable conditions, an evolution to another equilibrium state may be predicted, interpreted and explained. However, if this is the case, the system is no longer the same, once some of the parameters that characterise it have changed. Even in the simpler case where only quantitative composition changes, one starts with a reaction mixture, say reaction mixture 1 , and ends with another reaction mixture, say reaction mixture 2 . While the qualitative composition of the two reaction mixtures may be similar, the quantitative composition will necessarily be different. How different is another question. Thus, in the context of discussing evolutionary processes towards chemical equilibrium, the word system must be thoughtfully and carefully used to avoid ideas of discrete and localized variability, like some of the ACs in Table 1. To coherently discuss the evolution of reaction mixtures towards equilibrium states, the characteristic parameters of the whole system, at any given time, must be borne in mind throughout.

\section{CONCLUSIONS AND IMPLICATIONS FOR INSTRUCTION}

The previous discussion shows that some of the problematic excerpts identified may work as paraphrases of some of the ACs considered in the analysis. In teaching and learning situations such phrases, in the written form or verbalized, are likely to contribute to building or reinforcing ACs due to its potential as hidden persuaders. Indeed, language as a system of interpretation (Sutton, 1992) is crucial and critical for conceptual construction and development. To acknowledge and identify the broad range of meanings for the same words, or similar meanings for different words, that are likely to happen in educational settings is too difficult in daily classroom practices. This difficulty to identify word(s)/meaning(s) matches and mismatches applies to both chemistry technical words and common words used in chemistry with meanings different from those in daily usage or in other particular contexts. Research of this kind may be of help to raise chemistry teachers' awareness of learning problems rooted in language of the sort herein discussed. Further work in classroom settings will provide insights on the dimensions and extent of problematic words and phrases discussed above.

Nevertheless, vague and imprecise language (like that of excerpts identified, some of which are transcribed in Table 2):

- encapsulates unclear underlying reasoning, often encompassing contradiction and confounding interpretations with observations; 
- contributes to reducing chemistry to a world of symbols and equations, with excessive emphasis on mathematics, missing the essence of school chemistry, that is, matter transformations;

- appears consistent with some of the ACs referred to and discussed above and provides further evidence for a direct relationship between language used in textbooks and students'

ACs identified at various school levels (Anderson, 1990; Garnett, Garnett, \& Hackling, 1995).

Some of the problematic excerpts discussed resemble school chemistry jargon stimulated by task and performance oriented approaches, particularly evident in competitive educational systems, as upper secondary education in Portugal is. This standard language incorporates dominant school culture in which displaying technical language, regardless of meanings underlying it, appears overvalued. Assessment questions that can be successfully answered regurgitating pieces of information, allow impressions of learning, prevent students from passing through the stages of epistemological development (Monk, 1995), and are highly compatible with this perspective. Apparently, they allow students academic progress along with misunderstandings on fundamentals of school chemistry (Tsaparlis \& Kousathana, 1995). Moreover, they work as an incentive to this kind of chemistry learning illusion where standard phrases with technical words and a good deal of standard equations are ingredients. As thought and language are (mutually) dependent on each other, if there are language problems in textbooks, as words and phrases discussed above show, it is no wonder that students' misunderstandings appear so long lasting.

Most chemical reactions under appropriate conditions, particularly those in aqueous solution studied in the 10th and 12th years, are to be considered reversible, but research shows (e.g., Stavridou \& Solomonidou, 1989) that students consider changes of matter as chemical if radical and not reversible whereas physical change is regarded as non-radical and reversible. Furthermore, researchers report that students show serious difficulties in spontaneously referring to criteria invoking sub-microscopic aspects associated with matter transformations (Stavridou \& Solomonidou, 1989; Garnett, Garnett, \& Hackling, 1995; Pedrosa, Dias, Rebelo, \& Veiga, 1997). This may be an indication of a great distance, or even incompatibility, between concepts derived from everyday, familiar contexts and experiences, dominated by perceptions and common-sense, and scientific concepts.

\section{Chemical equilibrium: A major failure or the missing point of school chemistry?}

Correctness and the accuracy of conceptual language used in teaching resources are both of utmost importance when teaching for quality learning. These language requisites are required to describe observations and convey interpretations of matter and its transformations, the essence of chemistry meaningful learning. Teaching and learning resources, tools and approaches, therefore, must pay particular attention to distinguish observations from interpretations and to make levels of analysis explicit. This is required to avoid oversimplifications, namely by making quick and implicit transitions between levels of analysis, or between the actual world of matter and its transformations and (useful) representational worlds - physical, pictorial or mathematical. Models - that are built in our scientific and cultural heritage.

The exploratory study herein reported focused on some of textbooks due to their importance as curricular resources. However, the complexity of factors influencing chemistry learning is acknowledged, particularly that concerning teachers' role in the context and for the purpose of educational changes. Rop (1999) stresses that chemistry learning is influenced by many cultural factors, Rodriguez (1999) provides insights on learning to teach for "more 
culturally inclusive and socially relevant pedagogical strategies" and Jones, Rua, \& Carter (1998) explore Vygostky's work on the zone of proximal development to study and highlight the importance of verbal interactions between educators. These studies provide background knowledge on socio-cultural aspects intervening and shaping chemistry teachers' critical roles to mediate between students, school chemistry and real chemistry, where adequate room is available for chemistry education researchers' interventions. Chemistry textbooks, on the other hand, are important curricular resources as was reminded throughout this paper. It is hoped that this paper works as a modest incentive outside the group of chemistry teachers we have been working with, contributing to a broad cooperation between researchers and teachers.

Further research is required to extend the analysis to a larger sample of Portuguese secondary school textbooks and to test and evaluate the suggestions made on language and devise resources and approaches coherent with them. To follow-up this exploratory study, secondary school practising teachers will be involved in the analysis of textbooks to identify and discuss problematic language and approaches with reference to ACs reported in literature and shared by their own students. This team work with teachers also aims at devising teaching resources and approaches incorporating suggestions made in this paper and additional ones emerging from discussions on problematic language and approaches further identified in textbooks. To improve the reliability of problematic language and approaches and evaluate the validity of suggestions made in real classroom settings are major aspects that will guide teachers' involvement in future work on chemical equilibrium and related concepts.

AKNOWLEDGEMENT: Portuguese Ministry of Science and Technology for financial support to our research unit Molecular Physical Chemistry.

ADDRESS FOR CORRESPONDENCE: M. Arminda Pedrosa, Departamento de Química, Faculdade de Ciências e Tecnologia, Universidade de Coimbra, 3000 Coimbra, Portugal

Fax:+351-39-826541; email: apedrosa@ci.uc.pt

\section{REFERENCES}

Aikenhead, G. S. (1996). Science education: border crossing into the subculture of science. Studies in Science Education, 27, 1-52.

Anderson, B. (1990). Pupils' conceptions of matter and its transformations (age 12 - 16).

Studies in Science Education, 18, 53-85.

Atkin J. M. \& Helms, J. (1993). Getting serious about priorities in science education.

Studies in Science Education, 21, 1-20.

Banerjee, A. C. (1991). Misconceptions of students and teachers in chemical equilibrium. International Journal of Science Education, 13, 487-494.

Camacho, M. \& Good, R. (1989). Problem solving and chemical equilibrium: successful versus unsuccessful performance. Journal of Research in Science Teaching, 26, 251-272.

Chang, R. (1991). Chemistry. McGraw Hill, Inc.

Corrêa, C. \& Basto, F. P. (1998). Química - $12^{\circ}$ Ano. Porto, Porto Editora.

Driver, R., Guesne, E., \& Tiberghien, A. (1985). Children's ideas in science. Open University Press.

Driver, R., Squires, A., Rushworth, P., \& Wood-Robinson, V. (1994). Making sense of secondary science. London, Routledge.

Garnett, P. J., Garnett, P. J., \& Hackling, M. W. (1995). Students' alternative conceptions in chemistry: a review of research and implications for teaching and learning. Studies in Science Education, 25, 69-95. 
Gil, V. M. S. (1996). Química - $12^{\circ}$ Ano, Lisboa, Plátano Editora.

Griffiths, A. K. (1994). A critical analysis and synthesis of research on student's chemistry misconceptions. Paper presented at the International Seminar: Problem Solving and Misconceptions in Chemistry and Physics. Dortmund, Germany, University of Dortmund - ICASE.

Gunstone, R. F. (1994). The importance of specific science content in the enhancement of metacognition. In P. Fensham, R. Gunstone, \& R. White (eds.). The content of science: a constructivist approach to its teaching and learning. London: Falmer Press.

Gunstone, R., White, R., \& Fensham, P. (1988). Developments in style and purpose of research on the learning of science. Journal of research in Science Teaching, 25, 513-530.

Haidar, A. H (1997). Prospective chemistry teachers' conceptions of the conservation of matter and related concepts. Journal of Research in Science Teaching, 34, 181-197.

Johnstone, A. H., MacDonald, J. J., \& Webb, G. (1977) Chemical equilibrium and its conceptual difficulties. Education in Chemistry, 14, 169-171.

Jones, M.G., Rua, M. J., \& Carter, G. (1998). Science teachers' conceptual growth within Vygotsky's zone of proximal developement. Journal of Research in Science Teaching, 35, 967-985.

Leitão, A. \& Carmona, A. (1997). Química - $12^{\circ}$ Ano. Lisboa, Lisboa Editora.

McDermott, L.C. (1993). How we teach and how students learn. Australian and New Zealand Physicist, 30, 151-163.

Monk, M. (1995). On the identification of principles in science that might inform research into students' beliefs about natural phenomena. International Journal of Science Education, $17,565-573$.

Novak, J. D. (1984). Application of advances in learning theory and philosophy of science to the improvement of chemistry teaching. Journal of Chemical Education, 61, 607-612.

Osborne, R. \& Freyberg, P. (1985). Learning in science: the implication of children's science. Auckland: Heinemann.

Pedrosa, M. A., Dias, M. H., Rebelo, I. S., \& Veiga, J. (1997). Concepções relativas estados físicos e mudanças de estado manifestadas por estudantes dos ensinos secundário e superior. In didácticas/metodologias da educação. Departamento de Metodologias da Educação, Universidade do Minho, 355- 365.

Rodriguez, A. J. (1998). Strategies for counterresistance: toward sociotransformative constructivism and learning to teach science for diversity and understanding. Journal of Research in Science Teaching, 35, 589-622.

Rop, C. J. (1999). student perspectives on success in high school chemistry. Journal of Research in Science Teaching, 36, 221-237.

Stavridou, H. and Solomonidou, C. (1989). Physical phenomena-chemical phenomena: do pupils make the distinction?. International Journal of Science Education, 11, 83-92.

Sutton, C. (1992). Teaching science with language in mind: Chemistry and English. In M. Atlay et al. (eds.). Open Chemistry. London: Hodder \& Stoughton.

Tsaparlis, G. \& Kousathana, M. (1995). Students' common errors and misconceptions in solving molecular-equilibrium problems. In Proceedings of the $3^{\text {rd }}$ ECRICE (R.M. Janiuk, ed.), pp. 309-313. Lublin-Kazimierz, Poland: Maria Curie-Sklodowska University.

Tsaparlis, G., Kousathana, M., \& Niaz, M. (1998). Molecular-equilibrium problems: manipulation of logical structure and of m-demand, and their effect on student performance. Science Education, 82, 437-454.

White, R. T. (1992). Implications of recent research on learning for curriculum and assessment. Journal of Curriculum Studies, 24, 153-164. 